\title{
ALAT BANTU PENDARATAN VISUAL DI AIRPORT UNTUK MENDUKUNG KESELAMATAN PESAWAT
}

\author{
Primadi Candra Susanto ${ }^{1}$, Reza Fauzi Jaya Sakti ${ }^{2}$, Prima Widiyanto ${ }^{3}$ \\ 1,2,3 Institut Transportasi dan Logistik TRISAKTI, Jakarta, Indonesia \\ e-mail: primstrisakti@gmail.com, reza.jayasakti@gmail.com, primawidiyanto@gmail.com
}

\begin{abstract}
ABSTRAK
Tujuan penelitian ini adalah untuk memberikan tuntunan kepada pilot atau penerbang pada saat melakukan pendekatan menuju landasan sehingga dengan adanya Precision Approach Light System dan Airfield Lighting System, sebelum melakukan pendaratan dan berbagai prosedur landing, pilot atau penerbang terlebih dahulu harus melihat lokasi bandara secara visual, termasuk posisi runway dan semua itu tidak mungkin bisa dilakukan dengan baik tanpa adanya Airfield Lighting System untuk dapat menjamin pelayanan keamanan dan keselamatan penerbangan, maka seluruh fasilitas elektronika dan listrik harus memiliki kualitas yang memadai baik ditinjau dari aspek teknis maupun aspek operasional. Metode penelitian ini merupakan studi literatur dengan membandingkan beberapa teori yang ada, penelitian sebelumnya. Hasil temuan manfaat dari alat bantu pendaratan visual di airport adalah untuk memberikan tuntutan kepada pilot atau penerbang saat melakukan pendaratan menuju landasan dan manfaatnya untuk ketepatan pendaratan pesawat udara. Solusi untuk mengindari kecelakaan harus perawatan secara rutin terhadap perawatan empat belas instrumen atau varian cahaya. Masing-masing mempunyai peran vital dan makna khusu untuk mendukung kelancaran proses pendaratan. Dari penelitian ini dapat disimpulkan, bahwa Melalui metode pendekatan teknis deskriptif kualitatif dalam melakukan analisis pembahasan dapat disimpulkan bahwa dengan adanya alat bantu visual di landasan sangat berguna untuk keselamatan pesawat saat mendarat.
\end{abstract}

Keyword : Alat Bantu Pendaratan, Visual, Airport, Keselamatan 


\section{PENDAHULUAN}

Bandar udara adalah suatu tempat di darat, di laut atau di air dimana pesawat udara dapat mendarat menurunkan atau mengangkut penumpang dan barang, perbaikan atau pemeliharaan juga pengiriman bahan bakar dan kegiatan lainnya. Secara umum suatu bandar udara harus mampu melayani aktivitas perhubungan udara sesuai jam operasi (operating hours) dengan menjamin keselamatan penerbangan, kelancaran dan keteraturan penerbangan. Kegiatan angkutan udara dalam negeri (domestik) seluruhnya dilakukan oleh Perusahaan Penerbangan Nasional (Perusahaan Pemerintah dan Swasta), sedangkan untuk penerbangan luar negeri (internasional) dilakukan oleh perusahaan penerbangan asing dan perusahaan penerbangan nasional. Transportasi udara umumnya dibagi ke dalam tiga golongan, yakni angkutan udara, penerbangaan umum, dan militer. Kategori penerbangan swasta dan umum selain penerbangan terjadwal yang dilakukan perusahaan penerbangan (airlines) meliputi juga penerbangan pribadi dan yang digunakan oleh industri swasta dan komersiaal untuk mengirimkan barang ataupun alat-alat dan hasil produksi. Dalam kategori penerbangan umum juga termasuk kegiatan penerbangan yang sifatnya non-transport, misalnya untuk keperluan inspeksi penerbangan, pemadaman kebakaran, dan lain-lain.

Sejak awal mula penerbangan, pilot selalu memakai tanda-tanda di darat sebagai alat bantu navigasi ketika mengadakan approach ke sebuah lapangan terbang. Fasilitas bantu tersebut adalah salah satu prasarana penunjang operasi bandara, dan dibagi menjadi 2 kelompok, yaitu : a. Alat bantu pendaratan instrument / ILS (Instrumental Landing System), b. Alat bantu pendaratan visual / AFL (Airfield Lighting System) Alat Bantu Pendaratan Pesawat di bandar udara, akan dibahas mengenai Alat Bantu Pendaratan secara Instrument berupa Instrument Landing System (ILS) walaupun Runway Visual Range (RVR). Dengan adanya Instrument Landing System (ILS) maka walaupun cuaca kurang baik maka pesawat terbang dapat mendarat dengan selamat.

\section{Instrument Landing System adalah} alat bantu pendaratan instrumen (nonvisual) yang digunakan untuk membantu pilot dalam melakukan prosedur pendekatan dan pendaratan pesawat di suatu bandara, atau dengan kata lain IFR (Instrument Flight Rules) adalah cara menerbangkan pesawat tanpa melihat keluar, jadi hanya mengikuti panduan instrumen di cockpit pesawat sebagai rujukannya. Intinya, dengan radio navigasi selain GPS, pesawat akan terbang dari 
satu titik ke titik yang lain dengan mengikuti sinyal radio yang dinamakan VOR (VHF Omni Range) atau NDB (Non Directional Beacon). Peralatan ILS terdiri atas 3 subsistem yaitu : Localizer Adalah pemancar yang memberikan sinyal pemandu azimuth, mengenai kelurusan pesawat terhadap garis tengah landasan pacu, beroperasi pada daerah frekuensi $108 \mathrm{MHz}$ hingga 111,975 MHz - Glide Slope Adalah pemancar yang memberikan sinyal pemandu sudut luncur pendaratan, bekerja pada frekuensi UHF antara 328,6 MHz hingga 335,4 MHz Marker Beacon Adalah pemancar yang menginformasikan sisa jarak pesawat terhadap titik pendaratan, dioperasikan pada frekuensi $75 \mathrm{~Hz}$. Marker Beacon terdiri dari 3 buah, yaitu : a. Outer Marker (OM) yang terletak 3,5 - 6 nautical miles dari landasan pacu. Outer Marker dimodulasikan dengan sinyal $400 \mathrm{~Hz}$ b. Middle Marker (MM) yang terletak pada $1050 \pm 150$ meter dari landasan pacu dan dimodulasikan dengan frekuensi 1300 Hzc. Inner Marker (IM) terletak 75 - 450 meter dari landasan pacu dan dimodulasikan dengan sinyal 3000 Hz. Di Indonesia tidak dipasang IM mengingat ILS dioperasikan dengan kategori

\section{LANDASAN TEORI}

Landasan hukum yang dipakai untuk mengatur tentang kegiatan Air Traffic Control di Indonesia antara lain adalah : 1. Keputusan
Menteri Perhubungan Nomor 11 Tahun 2010 tentang Tatanan Kebandarudaraan Nasional. Pada Bab V tentang Rencana Induk Bandar Udara, dalam pasal 19 yang meliputi 2 (dua) ayat disebutkan sebagai berikut: Ayat (1) tahapan pelaksanaan pembangunan sebagaimana dimaksud dalam pasal 15 huruf d disebutkan mengutamakan optimalisasi fasilitas eksisting dan kemudahan pelaksanaan pembangunan di lapangan (implementatif); Ayat (2) tahapan pelaksanaan pembangunan sebagaimana dimaksud pada ayat (1) dimaksudkan untuk mendapatkan efisiensi dan efektivitas rencana pelaksanaan pembangunan berdasarkan hasil perhitungana dan kajian/analisis terhadap : a. Rencana tata guna lahan hingga desain tahap akhir (ultimate phase); b. Kebutuhan fasilitas badnar udara dengan skala prioritas yang mempertimbangkan faktor kebutuhan dan ketersediaan anggaran; c. Rencana tata letak fasilitas bandar udara; d. rencana pengembangan fasilitas bandar udara tiap-tiap tahapan pembangunan hingga akhir . 2 . Keputusan Direktur Jenderal Perhubungan Udara Nomor SKEP 113/VI/2002 tentang Kriteria Penempatan Fasilitas Elektronika dan Listrik Penerbangan.

Pada Bab I disebutkan bahwa pada setiap penyelenggara bandar udara harus menempatkan fasilitas elektronika dan listrik 
penerbangan sesuai dengan kriteria penempatan fasilitas elektronika dan listrik penerbangan yang menyebutkan untuk beroperasinya secara optimal peralatan fasilitas elektronika dan listrik penerbangan perlu ditata penempatan peralatan tersebut ditinjau dari aspek teknis maupun dari aspek operasional. Kriteria penempatan peralatan tersebut selanjutnya dibaklukan dan menjadi acuan di dalam pembangunan dan pemasanagan fasilitas elektronika dan listrik khususnya fasilitas listrik penerbangan. 3. Keputusan Direktur Jenderal Perhubungan Nomor SKEP/114/VI/2002 tentang Standar Gambar Instalasi Penerangan Bandar Udara (Airfied Lighting System). Pada Bab II di dalam SKEP/114/VI/2002 ini tentang ketentuan umum yang mendefinisikan pengertian-pengertian: a. Sistim Penerangan Bandar Udara (Airfied Lighting System) adalah alat bantu pendaratan visual yang berfungsi membantu dan melayani pesawat udara yang melakukan tinggal landas, mendarat dan melakukan taxi agar dapat bergerak secara efisien dan aman. Fasilitas ini terdiri dari lampu-lampu khusus yang memberikan isyarat dan informasi secara visual kepada penerbang, terutama pada waktu penerbangan yang akan melakukan pendaratan atau tinggal landas. Isyarat dan visual ini disediakan dengan mengatur konfigurasi warna, dan intensitas cahaya dari lampu-lampu khusus tersebut. Pada umumnya sewaktu akan melakukan pendaratan atau tinggal landas, penerbangan lebih mengandalkan penglihatannya keluar pesawat dari pada instrument yang terdapat pada cockpit pesawatnya. b. Intensitas pancaran cahaya peralatan penerangan bandar udara adalah intensitas cahaya yang dipancarkan oleh lampu penerbangan bandar udara dan dapat dikelompokkan pada high intensity, medium intensity dan low intensity. Besaran intensitas pancaran cahaya tersebut harus memenuhi standar ICAO dan sesuai dengan spesifikasi teknis- yang telah ditentukan. Intensitas yang dihasilkan lampu tergantung juga pada besaran konsumsi daya (watt) lampu yang diperguanakan (high intensity = 100 watt, 150 watt dan 200 watt, medium intensity $=45$ watt 100 watt dan low intensity $=30$ watt -45 watt). c. Gambar instalasi sistim peneranagan bandar udara adalah gambar desain penempatan, konfigurasi, dan pelaksanaan instalasi dari sistim penerangan bandar udara. Area Navigation (RNAV) adalah suatu metode bernavigasi yang mengizinkan operasi pesawat terbang pada jalur penerbangan manapun yang diinginkan dalam cakupan pancaran peralatan navigasi atau batas kemampuan alat bantu tersendiri. d. Approach Lighting System adalah suatu instrument approach prosedure dimana lampu pada dua ambang landasan untuk pendaratan dan lepas landas telah terpenuhi. e. 
Threshold (THR) adalah awal dari sautu bagian runway yang dapat digunakan untuk pendaratan.

Dalam (KaltimProv:2019) AFL System adalah alat bantu pendaratan visual yang berfungsi membantu dan melayani pesawat terbang selama tinggal landas, mendarat dan melakukan taxi agar dapat bergerak secara efisien dan aman.

Dalam Dept Teknik Sipil 2011, Bandar Udara merupakan suatu fasilitas sebagai perantara (interface) antara transportasi udata dengan transportasi darat, yang secara umum fungsinya sama dengan terminal, yakni sebagai : 1. Tempat pelayanan bagi keberangkatan / kedatangan pesawat. 2. Untuk bongkar / muat barang atau naik / turun penumpang. 3. Tempat perpindahan (interchange) antar moda transportasi udara dengan moda transportasi yang sama (transit) atau dengan moda yang lainnya. 4. Tempat untuk penyimpanan barang (storage) selama proses pengurusan dokumen. 5. Sebagai tempat untuk pengisihan bahan bakar, perawatan dan pemeriksanaan kondisi pesawat sebelum dinyatakan layak untuk terbang.

Dalam Kepmenhub, Di Indonesia klasifikasi bandar udara sesuai dengan Keputusan Menteri Perhubungan No. 36 Tahun 1993 didasarkan pada beberapa kriteria berikut ini : 1. Komponen jasa angkutan udara. 2. Komponen pelayananan keselamatan dan keamanan penerbangan. 3. Komponen daya tampung bandar udara (landasan pacu dan tempat parkir pesawat). 4. Komponen fasilitas keselamatan penerbangan (fasilitas elektronika dan listrik yang menunjang operasi fasilitas keselamatan penerbangan). 5. Komponen status dan fungsi bandar udara dalam konteks keterkaitannya dengan lingkungan sekitarnya.

Menurut (Horonjeff:1988) Pengertian Lalu Lintas Udara Lalu lintas udara merupakan suatu bentuk pergerakan dari pesawat terbang di dalam ruang udara. Dalam hal ini lalu lintas udara secara umum dapat dipisahkan menjadi dua, yakni lalu lintas di sekitar bandar udara ketika pesawat akan tinggal landas (take off) ataupun mendarat (landing), serta lalu lintas udara di luar otoritas bandar udara (airspace).

\section{Menurut (Zainuddin:1986) Alat-alat} Bantu Terminal Eksternal yang Digunakan di Atas Daratan 1. Sistem Pendaratan dengan Instrumen Metode yang paling banyak digunakan adalah sistem pendaratan dengan instrumen (Instrument landing system / ILS). Sistem ini terdiri dari dua pemancar radio yang terletak di bandar udara yang bersangkutan, yang satu disebut penentu letak (localizer) dan yang lain disebut kemiringan luncur (glide slope). Penentu letak memberikan petunjuk kepada penerbang, apakah mereka berada di kiri atau di kanan jalur yang tepat untuk pendaratan di landasan pacu. Kemiringan luncur 
menunjukkan sudut luncur di bawah yang tepat menuju landasan pacu (sekitar 20 - 30). Fungsi dari penentu letak dan fasilitas kemiringan luncur dipengaruhi oleh kedekatannya terhadap benda-benda yang bergerak, seperti gerakan kendaraan dan pesawat terbang. Benda-benda tetap yang terletak di dekat penentu letak dan fasilitas kemiringan luncur juga dapat mengganggu sinyal-sinyal radio. Perubahan kemiringan yang tiba-tiba di daerah sekitar antena penentu letak juga tidak diperbolehkan karena akan mengakibatkan sinyal tidak dipacarkan dengan semestinya.

\section{METODE PENELITIAN}

Metode penelitian yang digunakan adalah metode penelitian kualitatif melalui studi literatur, kajian pustaka dari sudut pandang indikator keselamatan penerbangan dan menganalisa suatu rangkaian system prosedur pendaratan pesawat terbang dengan panduan dari Precision Approach Light System dan Airfield Lighting System, dalam studi tersebut akan jabarkan tingkat eksplanasi peranan alat bantu pendaratan visual. Analisis data yang digunakan dalam penelitian ini merupakan analisa deskriptif, Penelitian deskriptif bertujuan untuk memberikan gambaran dalam bentuk deskripsi berupa kata-kata didukung dengan lieratur mengenai subjek penelitian dari pengamatan terhadap suatu fenomena. Hasil penelitian tersebut kemudian dianalisis untuk menemukan indikator untuk mencegah kecelakaan dalam proses pendaratan pesawat.

\section{PEMBAHASAN}

Masing-masing mempunyai peran vital dan makna khusu untuk mendukung kelancaran proses pendaratan. Agar lebih jelas, berikut daftar lima belas instrumen Airfield Lighting System.

\section{Approach Light}

Rambu penerangan untuk pendekatan yang dipasang pada perpanjangan landasan pacu. Fungsinya sebagai petunjuk kepada penerbang tentang posisi, arah pendaratan dan jarak terhadap ambang landasan pada saat pendaratan. Biasanya approach light berwarna putih.

\section{Runway Threshold Identification Light (RTIL)}

Rambu penerangan yang berfungsi sebagai penunjuk awal dimulainya runway. Lampu RTIL biasanya berwarna putih dan berkedip-kedip. Tak seperti approach light, RTIL hanya memiliki dua lampu di setiap sisi.

\section{Threshold Light}

Rambu penerangan yang berfungsi sebagai penunjuk ambang batas landasan. Biasanya dipasang pada batas ambang landasan pacu dengan jarak tertentu memancarkan cahaya 
hijau jika dilihat oleh penerbang pada arah pendaratan.

\section{Runway Edge Light}

Rambu penerangan landasan pacu, terdiri dari lampu-lampu yang dipasang pada jarak tertentu di tepi kiri dan kanan landasan pacu untuk memberi tuntunan kepada penerbang pada pendaratan dan tinggal landas pesawat terbang disiang hari pada cuaca buruk, atau pada malam hari. Biasanya runway edge light terdiri dari berbagai warna, bergantung pada konsisi, seperti putih/putih, putih/kuning, putih/merah, dan kuning/merah.

\section{Runway End Light}

Rambu penerangan sebagai alat bantu untuk menunjukan batas akhir atau ujung landasan. Intrumen ini dipasang pada batas ambang landasan pacu dengan memancarkan cahaya merah apabila dilihat oleh penerbang yang akan tinggal landas.

\section{Taxiway Light}

Rambu penerangan yang terdiri dari lampu-lampu memancarkan cahaya biru yang dipasang pada tepi kiri dan kanan taxiway pada jarak-jarak tertentu dan berfungsi memandu penerbang untuk mengemudikan pesawat terbangnya dari landasan pacu ke dan atau dari tempat parkir pesawat.

7. Precision Approach Path Indicator (PAPI) dan Visual Approach Slope Indicator System (VASIS)
Rambu penerangan yang memancarkan cahaya untuk memberi informasi kepada penerbangan mengenai sudut luncur yang benar, dan memandu penerbang melakukan pendekatan menuju titik pendaratan pada daerah touchdown. Biasanya PAPI mengeluarkan empat cahaya, merah dan atau putih. Bila pesawat berada dalam posisi tepat, maka lampu akan terdiri dari putih-putih-merah-merah.

\section{Obstruction Aviation Lights}

Rambu penerangan yang berfungsi sebagai tanda untuk menunjukan ketinggian suatu bangunan yang dapat menyebabkan gangguan atau rintangan pada penerbangan.

\section{Flood Light}

Rambu penerangan untuk menerangi tempat parkir pesawat terbang diwaktu siang hari pada cuaca buruk atau malam hari pada saat ada pesawat terbang yang menginap atau parkir.

\section{Rotating Beacon}

Rambu penerangan petunjuk lokasi bandar udara, terdiri dari dua sumber cahaya bertolak belakang yang dipasang pada as yang dapat berputar, sehingga dapat memancarkan cahaya berputar dengan warna hijau dan putih pada umumnya Rotating Beacon dipasang diatas tower.

\section{Turning Area Light}

Rambu penerangan untuk memberi tanda bahwa didaerah ini terdapat tempat pemutaran pesawat terbang.

\section{Apron Light}


Rambu penerangan yang terdiri dari lampu-lampu yang memancarkan cahaya merah yang dipasang di tepi Apron untuk memberi tanda batas pinggir Apron.

\section{Sequence Flashing Light (SQFL)}

Lampu penerangan berkedip berurutan pada arah pendekatan. SQFL dipasang pada Bar 1 s/d Bar 21 Approach Light System.

\section{Traffic Light}

Rambu penerangan berfungsi sebagai tanda untuk pengaturan kendaraan umum yang dikhawatrikan akan dapat menyebabkan gangguan terhadap pesawat terbang yang sedang mendarat.

\section{Wind Cone}

Rambu penerangan menunjukan arah angin bagi pendaratan atau lepas landas suatu pesawat terbang.

\section{HASIL TEMUAN}

Seiring berjalannya waktu, sudah banyak bandara yang dilengkapi dengan Instrument Landing Systems (ILS) yang canggih, sehingga para pilot bisa mendarat dan mengudara bahkan dalam kondisi berkabut. Data penyelarasan sumbu landas pacu dipancarkan oleh radio dari antena yang disebut localiser, yang kerap kali ditemui di ujung landasan. Dari sinyal yang dipancarkan, pilot dapat menghitung orientasi sinyal kiri dan kanan yang diterima, dan mensejajarkan posisi pesawat dengan landas pacu. Instrumen on-board juga memungkinkan pilot mengetahui posisi pesawat terhadap landas pacu dari perbedaan intensitas sinyal yang diterima. Data yang dikirim oleh Instrument Landing Systems akan muncul di layar yang berada di dalam kokpit, bahkan beberapa model Instrument Landing Systems mampu mengirimkan perintah pendaratan langsung ke sistem auto-pilot. Apabila kita berpikiran lampu landas pacu merupakan bagian dari Instrument Landing Systems, maka kita salah besar. Karena lampu pada landas pacu merupakan bagian dari Approach Lighting System yang juga berperan dalam membantu pilot melakukan pendaratan ketika kondisi berkabut. Instrument Landing Systems sendiri memiliki tiga kategori berbeda, yaitu kategori I, II, dan III. Masingmasing kategori memiliki ketinggian minimum untuk mendarat dan jarak pandang yang berbeda-beda. Terlepas dari kategori tersebut, di setiap pesawat harus dilengkapi dengan onboard instrument ini dan awak kapal yang terlatih untuk membaca informasi yang dikeluarkan oleh alat ini. Dalam prakteknya, pengendali lalu lintas udara bertanggung jawab untuk membimbing pesawat terbang menuju localiser landasan pacu saat mendekati bandara, walaupun beberapa pesawat mungkin menggunakan Instrument Landing Systems secara bersamaan, menunjukkan rute untuk mengikuti dan menerapkan jarak pengaman yang diperlukan di antara setiap pesawat masuk yang dalam kondisi low-visibility perlu lebih 
besar dari biasanya. Keberadaan Instrument Landing Systems juga bisa dijadikan sebagai pengatur keberadaan pesawat di sekitar landas pacu, sehingga jarak aman antar pesawat tetap terjaga, baik dalam kondisi berkabut ataupun cerah.

\section{KESIMPULAN}

Lembaga Penyelenggara Pelayanan Navigasi Penerbangan Indonesia (LPPNPI) atau dikenal dengan AirNav Indonesia akan memasang Instrumen Landing System (ILS) di 13 Bandara. Rinciannya, delapan bandara melakukan penggantian ILS, sementara lima bandara lain untuk pertama kalinya dipasang Instrumen Landing System. Selain itu, AirNav juga melakukan perbaikan Instrumen Landing System di 16 bandara. Tanpa Instrumen Landing System, bandara yang punya potensi mendukung pariwisata terbentur membatasi penerbangan, dimana pesawat tidak dapat melakukan pendaratan di malam hari. Ada juga bandara yang hanya bisa didarati dalam kondisi cuaca cerah, lantaran area landas pacu (runway) terselimuti kabut atau asap.

Dirunut dari definisinya, Instrumen Landing System adalah sistem pemandu pendaratan pesawat dengan menggunakan instrument elektronika. Sistem ini membantu pesawat udara untuk mendarat tepat pada centre line (garis tengah) runway dan dengan sudut pendaratan yang tepat. Pemanduan dilakukan agar pilot mengetahui jarak pesawat terhadap area pendaratan (touchdown zone) pada runway. Pemanduan dilakukan untuk mengatur posisi kanan kiri (center line) pesawat, sehingga dapat landing dengan tepat di garis tengah landasan. Pemanduan dilakukan juga untuk mengatur posisi atas bawah pesawat, sehingga dapat landing dengan tepat pada sudut $\pm 3^{\circ}$ terhadap landasan. Instrumen Landing System terdiri dari 3 komponen peralatan berdasarkan fungsi pemanduannya yaitu Marker Beacon, Localizer, dan Glide Slope.

\section{DAFTAR PUSTAKA}

Achmad Zainuddin, 1986. Selintas Pelabuhan

Udara, Yogyakarta : Ananda.

Departemen Teknik Sipil ITB, 2001 "Dasar-

dasar Transportasi, Bandung : ITB Press.

Robert Horonjeff, 1988, "Perencanaan dan

Perancangan Bandar Udara Jilid 1, Jakarta : Erlangga.

Keputusan Menteri Perhubungan No. 36 Tahun 1993 Tentang Klasifikasi Bandar Udara

\section{INTERNET}

https://kaltimprov.go.id/berita/karenapemasangan-lampu-runway-bandaraapt-pranoto-akan-ditutup-20-hari

(Diakses Pada Tanggal 26 Agustus 2020) 
www.kabarpenumpang.com (Diakses Pada

Tanggal 26 Agustus 2020) 